\title{
Consumer Views on Health Applications of Consumer Digital Data and Health Privacy Among US Adults: Qualitative Interview Study
}

David Grande ${ }^{1,2}$, MD, MPA; Xochitl Luna Marti ${ }^{1}$, MPH; Raina M Merchant ${ }^{3}$, MD, MSHP; David A Asch ${ }^{1}$, MD, MBA; Abby Dolan ${ }^{3}$, MPH; Meghana Sharma ${ }^{1}$, MPH; Carolyn C Cannuscio ${ }^{4}$, SCD

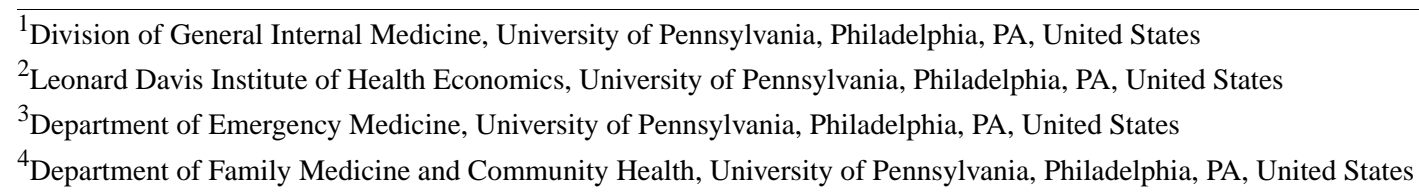

Corresponding Author:

David Grande, MD, MPA

Division of General Internal Medicine

University of Pennsylvania

3641 Locust Walk

CPC 407

Philadelphia, PA, 19081

United States

Phone: 12155733804

Fax: 12158980229

Email: dgrande@wharton.upenn.edu

\section{Abstract}

Background: In 2020, the number of internet users surpassed 4.6 billion. Individuals who create and share digital data can leave a trail of information about their habits and preferences that collectively generate a digital footprint. Studies have shown that digital footprints can reveal important information regarding an individual's health status, ranging from diet and exercise to depression. Uses of digital applications have accelerated during the COVID-19 pandemic where public health organizations have utilized technology to reduce the burden of transmission, ultimately leading to policy discussions about digital health privacy. Though US consumers report feeling concerned about the way their personal data is used, they continue to use digital technologies.

Objective: This study aimed to understand the extent to which consumers recognize possible health applications of their digital data and identify their most salient concerns around digital health privacy.

Methods: We conducted semistructured interviews with a diverse national sample of US adults from November 2018 to January 2019. Participants were recruited from the Ipsos KnowledgePanel, a nationally representative panel. Participants were asked to reflect on their own use of digital technology, rate various sources of digital information, and consider several hypothetical scenarios with varying sources and health-related applications of personal digital information.

Results: The final cohort included a diverse national sample of 45 US consumers. Participants were generally unaware what consumer digital data might reveal about their health. They also revealed limited knowledge of current data collection and aggregation practices. When responding to specific scenarios with health-related applications of data, they had difficulty weighing the benefits and harms but expressed a desire for privacy protection. They saw benefits in using digital data to improve health, but wanted limits to health programs' use of consumer digital data.

Conclusions: Current privacy restrictions on health-related data are premised on the notion that these data are derived only from medical encounters. Given that an increasing amount of health-related data is derived from digital footprints in consumer settings, our findings suggest the need for greater transparency of data collection and uses, and broader health privacy protections.

(J Med Internet Res 2021;23(6):e29395) doi: 10.2196/29395

\section{KEYWORDS}

health privacy; digital health privacy; privacy law; health law; digital epidemiology 


\section{Introduction}

In 2020, internet users spent 1.25 billion years online. The average internet user spends 6 hours and 43 minutes online each day [1], leaving a trail of information about his/her habits and preferences that collectively generates a digital footprint.

A consumer's digital footprint can reveal health-related behaviors, such as diet and physical activity, that can predict health [2]. For example, data from social media sites, including Twitter and Facebook, can be used to screen for signs of depression, suicidal ideation, and sleep disorders based on user activity and language patterns [3-6]. These applications of data toward health purposes erase past distinctions between health and nonhealth data $[7,8]$.

The COVID-19 pandemic has accelerated these applications. Smartphone location services and cashless transactions have been used to identify and track COVID-19-positive individuals [9]. Social media posts have been used to track reports of physical symptoms of COVID-19 and mental health sequelae of the pandemic [10,11]. Apple and Google have updated their smartphone operating systems to enable tracking of human-to-human interactions to enable digital contact tracing [12]. These public health applications of consumer digital data have triggered global debates and urgent policy discussions about digital health privacy [13].

A majority of Americans simultaneously reported feeling concerned about how their personal data are being used and yet continue to use digital technologies. Many believe it is impossible to go through daily life without having personal data collected by companies or the government, with $80 \%$ feeling they lack control over what data are collected and 63\% admitting having little to no understanding about data privacy laws and regulations [14].

We interviewed a diverse sample of American consumers to evaluate their awareness of the health applications of their digital data and identify their privacy views and concerns.

\section{Methods}

\section{Participants}

Interviews were conducted between November 1, 2018, and January 31, 2019. Participants were identified from the web-enabled Ipsos KnowledgePanel, a probability-based panel designed to be representative of the US population [15]. For this study, Ipsos provided the contact information of 200 participants drawn from the nationally representative panel with even distribution for various demographic variables (gender, race, age, household income, and geographic region) to ensure diversity in the study sample. From these, team members (XLM and $\mathrm{AL}$ ) completed 45 interviews, ensuring equal proportions of participants were included from each category so that the sample of 45 reflected the larger sample of 200. Participants who completed the interview were paid US \$50.

This study protocol was reviewed by the Institutional Review Board of the University of Pennsylvania and declared exempt. Verbal consent was obtained from participants prior to their interview. All results are reported following the Standards for Reporting Qualitative Research (SRQR) reporting guidelines.

\section{Design}

Telephone interviews were conducted using a semistructured qualitative interview guide (Multimedia Appendix 1). This guide was informed by a consequential ethics framework, in which the presence or absence of a substantial risk of harm from a loss of privacy determines the need for protections [16]. The guide asked consumers to reflect on their own use of digital technology, evaluate sources of digital information, and consider several hypothetical scenarios with varying uses of digital information (scenarios shown in Table 1). While the scenarios were hypothetical, they were developed based on plausible use cases in today's landscape of consumer digital data. The interviews lasted 30 to 45 minutes, and were conducted by research coordinators ( $\mathrm{AL}$ and XLM) trained in qualitative interviewing methods. The audio recordings were sent to a professional transcription service (ADA Transcription) where they were deidentified. Transcripts were uploaded to NVivo Version 12 for data analysis [17]. 
Table 1. Scenarios.

\begin{tabular}{|c|c|c|c|c|}
\hline No. & Text & Source & User & Use \\
\hline 1 & $\begin{array}{l}\text { Your health insurance company is trying to find ways to keep people healthier and } \\
\text { save money. They have found that consumers that buy certain kinds of food are more } \\
\text { likely to develop diabetes. The insurance company is planning a program where they } \\
\text { will access the grocery shopping records of their patients from grocery stores. The } \\
\text { health insurance company will use this information to find out who is at high risk of } \\
\text { developing diabetes, then send those people tips and advice on how they can prevent } \\
\text { diabetes by making changes to the food they buy. }\end{array}$ & $\begin{array}{l}\text { Grocery shopping } \\
\text { records }\end{array}$ & $\begin{array}{l}\text { Health insur- } \\
\text { ance company }\end{array}$ & Prevent diabetes \\
\hline 2 & $\begin{array}{l}\text { Your doctor's office is trying to find ways to prevent people from getting sick and } \\
\text { needing to go to the hospital. They have found that patients that search on the internet } \\
\text { for certain symptoms are more likely to get sick and need to go to an emergency room. } \\
\text { Your doctor's office is planning a new program where they will access internet } \\
\text { searches of their patients and contact patients that search for certain symptoms to try } \\
\text { to start treatment sooner. }\end{array}$ & $\begin{array}{l}\text { Internet search } \\
\text { history }\end{array}$ & Doctor's office & $\begin{array}{l}\text { Diagnose disease } \\
\text { earlier }\end{array}$ \\
\hline 3 & $\begin{array}{l}\text { University researchers are trying to find ways to prevent cancer. Researchers at a } \\
\text { nearby university hospital are starting a research study where they will track patients } \\
\text { over time to try to determine causes of cancer. In addition to using medical records, } \\
\text { the research team will use location information from patient's smartphones so they } \\
\text { can study how the places where people spend most of their time impact their risk of } \\
\text { getting cancer. The researchers want to use this knowledge to help develop public } \\
\text { health strategies in the future that could reduce the number of people with cancer. }\end{array}$ & $\begin{array}{l}\text { Electronic health } \\
\text { record and loca- } \\
\text { tion data from a } \\
\text { smartphone }\end{array}$ & $\begin{array}{l}\text { University re- } \\
\text { searchers }\end{array}$ & $\begin{array}{l}\text { Research to iden- } \\
\text { tify risk factors } \\
\text { for cancer }\end{array}$ \\
\hline 4 & $\begin{array}{l}\text { DigiHealth is a company selling a new smartphone app that can automatically collect } \\
\text { and store information on places users visit and the food they eat so that it can give } \\
\text { advice on ways to lower their risk of obesity. The app tracks where users go using lo- } \\
\text { cation services on their smartphone and tracks what they eat by having them upload } \\
\text { a picture of their meals. DigiHealth is able to offer the app for free because it shares } \\
\text { user information with advertisers so they can send out grocery coupons. }\end{array}$ & $\begin{array}{l}\text { Location data and } \\
\text { photos from a } \\
\text { smartphone }\end{array}$ & $\begin{array}{l}\text { Technology } \\
\text { company }\end{array}$ & $\begin{array}{l}\text { Send grocery } \\
\text { coupons for } \\
\text { healthier foods to } \\
\text { prevent obesity }\end{array}$ \\
\hline
\end{tabular}

\section{Analysis}

The study team developed a codebook through line-by-line iterative reading and notation of transcripts, which produced 12 key codes [18]. Some codes were used a priori in order to compare data from consumers to the data from similar interviews conducted with experts [7]. Two research coordinators used the codebook to complete coding (AL and XLM). In order to establish agreement, five interview transcripts were double coded. Interrater reliability was high, with overall agreement (97.5\%) and Cohen kappa of 0.7. After agreement was established, the remaining transcripts were coded individually. Interviews were coded sequentially in the order they were conducted. A memo was written, and it thematically summarized the content of each code. These memos were reviewed collectively by the study team in order to identify salient findings. The study team found that they were no longer learning new information in the process of coding new transcripts. Therefore, through coding and analysis meetings, key study personnel reached a consensus that thematic saturation was reached. The results from these interviews are reported along with supporting quotes to highlight relevant findings.

\section{Results}

\section{Participants}

The sampling methods produced a final cohort of 45 consumers with diversity in gender, race, age, household income, and geographical distribution (Table 2). 
Table 2. Demographics of the participants $(\mathrm{N}=45)$.

\begin{tabular}{|c|c|}
\hline Characteristic & Value, n $(\%)$ \\
\hline \multicolumn{2}{|l|}{ Gender } \\
\hline Male & $24(53 \%)$ \\
\hline Female & $21(47 \%)$ \\
\hline \multicolumn{2}{|l|}{ Race } \\
\hline Minority (non-White) & $22(49 \%)$ \\
\hline White/Caucasian & $23(51 \%)$ \\
\hline \multicolumn{2}{|l|}{ Age (years) } \\
\hline $18-30$ & $14(31 \%)$ \\
\hline $31-45$ & $10(22 \%)$ \\
\hline $46-60$ & $11(24 \%)$ \\
\hline$>60$ & $10(22 \%)$ \\
\hline \multicolumn{2}{|l|}{ Household income (US\$) } \\
\hline$\leq 24,999$ & $10(22 \%)$ \\
\hline $25,000-49,999$ & $11(24 \%)$ \\
\hline $50,000-99,999$ & $13(29 \%)$ \\
\hline$\geq 100,000$ & $11(24 \%)$ \\
\hline \multicolumn{2}{|l|}{ Region } \\
\hline Midwest & $12(27 \%)$ \\
\hline Northeast & $10(22 \%)$ \\
\hline South & $13(29 \%)$ \\
\hline West & $10(22 \%)$ \\
\hline \multicolumn{2}{|l|}{ Education } \\
\hline Less than high school & $3(6 \%)$ \\
\hline High school & $12(27 \%)$ \\
\hline Some college & $13(29 \%)$ \\
\hline Bachelor's degree or higher & $17(38 \%)$ \\
\hline
\end{tabular}

\section{Part 1: Views on Digital Privacy and Health}

digital health privacy. Key themes are described below, and The first portion of participant interviews focused on consumers' illustrative quotes are presented in Table 3. understanding of current data use as well as their views on 
Table 3. Key themes from consumer interviews.

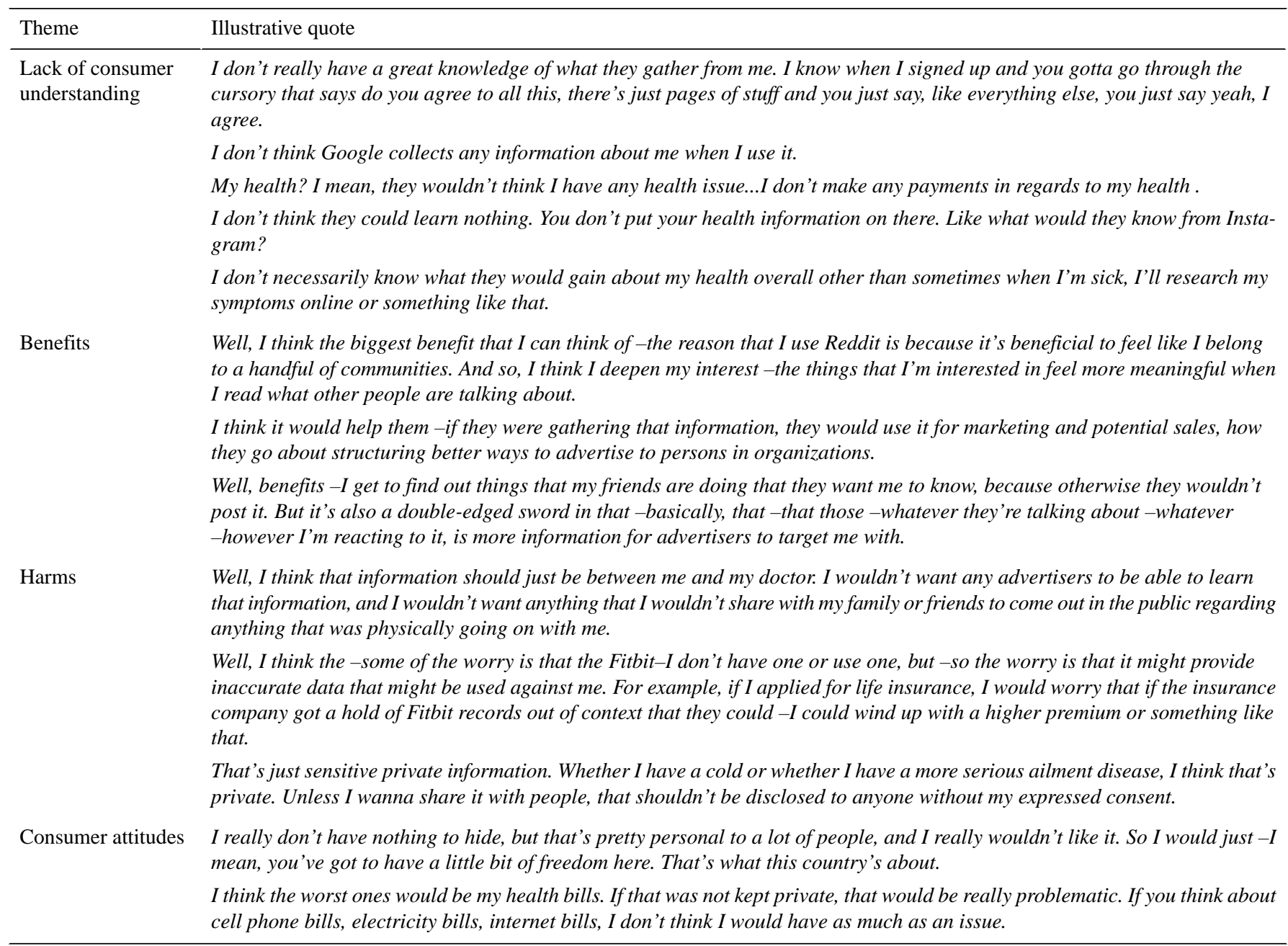

\section{Lack of Consumer Understanding of Digital Data Practices}

Few participants could express a basic understanding of digital data collection practices, including how information is routinely tracked, stored, and subsequently used by third parties. Some were unaware that by downloading and using an app (eg, Facebook), they had consented to data collection. Participants who were aware that their data were being collected generally assumed the data were being used only by the entity collecting it and were not shared with third parties. Almost none of the participants named ways in which data are aggregated across sources and over time, a common practice by marketers to build profiles of individual consumers.

Participants generally did not recognize the connections between their digital data and inferences about their health. They were not able to conceptualize health information outside of a traditional definition of health care data. They were unaware that predictions or inferences about their health status could be drawn from sources like internet browsing information or social media posts.

\section{Perceived Benefits and Harms of Digital Data Practices}

Participants noted benefits of digital data collection to consumers and companies. They described the benefits of advertising highly tailored to their interests. They discussed convenience derived from data tracking. They discussed health benefits when prompted by specific health-related scenarios, but rarely mentioned them during other parts of the interview despite the interviewers introducing the study focus as related to health.

Indeed, most privacy concerns were broad rather than specific to health. Participants worried that their information could affect their finances, particularly that insurance coverage could be lost or premiums raised because of health information being made available to their insurer. Some participants feared losing employment opportunities if their information, especially health information, was available to an employer.

For some participants, the main harm was the intrusiveness of the digital data collection practices of the government, commercial companies like health insurers, and even health care providers, with access to information that some felt should remain private.

Participants split into two points of view when weighing tradeoffs between the benefits and risks of digital data collection and use. Some felt that it was a choice to give up privacy for convenience or other benefits. Several of these participants discussed tradeoffs in transactional terms. The use of discount cards, apps, and other programs naturally involves relinquishing some privacy, which is sometimes a worthwhile choice. Others described data tracking and sharing as inescapable. These 
participants did not consider these privacy risks acceptable but struggled to articulate how to avoid them.

\section{Attitudes Regarding Digital Privacy}

Despite a lack of knowledge on data privacy issues, participants strongly endorsed the significance of data privacy, based partly on a right to privacy and on concerns about harms.

When asked about privacy preferences for different types of data (health information, internet searches, and financial information), participants consistently expressed the greatest concern if their health information was not kept private. However, participants did not understand that data generated outside of health care could also be used to make inferences about their health.

\section{Part 2: Health-Related Applications of Consumer Digital Data}

To make health applications of digital data more salient to participants, we prompted them with a series of hypothetical scenarios (Table 1) representing various sources, uses, and users of digital information for health purposes. For each scenario, participants were asked to provide their overall impression, describe what they liked and disliked about it, identify limits or protections they desired, and share whether they would want to participate.

Although participants' responses to each scenario varied, certain themes were consistent. Participants appreciated the health benefits that could be achieved through the programs, including interventions to improve individual or population health, research to make advances in health care, and efforts to reduce health care costs. However, participants often expressed concern that many uses seemed too invasive and that their data might be used for other purposes beyond what was intended. They often desired protections so that data could be used only for the originally intended purpose, data could be kept private and secure, and participation could be voluntary and require consent. Table 4 provides illustrative quotes for the benefits, risks, and protections discussed by participants for each scenario. 
Table 4. Consumer perspectives on digital data use scenarios (illustrative quotes).

\begin{tabular}{|c|c|c|c|c|}
\hline Scenario $^{\mathrm{a}}$ ( $\%$ favorable $)$ & $\begin{array}{l}\text { Rated favorable } \\
(\mathrm{N}=45), \mathrm{n}(\%)\end{array}$ & Benefit quotes & Risk quotes & Desired protection quotes \\
\hline $\begin{array}{l}\text { A health insurance company } \\
\text { accesses data on consumers } \\
\text { grocery store purchases to } \\
\text { identify individuals at high } \\
\text { risk for developing diabetes } \\
\text { and sends them healthy eat- } \\
\text { ing tips. }\end{array}$ & $20(44 \%)$ & $\begin{array}{l}\text { I think it could give some valu- } \\
\text { able information. And especial- } \\
\text { ly if someone is unaware that } \\
\text { their purchases are causing } \\
\text { problems. } \\
\text { The idea that someone is going } \\
\text { to help me because I might not } \\
\text { have that information that this } \\
\text { product might not be good for } \\
\text { my health, that is wonderful. }\end{array}$ & $\begin{array}{l}\text { How much do you want them to } \\
\text { stick their nose into what you're } \\
\text { doing? ... Now they want to tell } \\
\text { you what to eat? They could easily } \\
\text { raise the premium on it. I know } \\
\text { they would. } \\
\text { That's just my personal choice if } \\
\text { that's what I wanna purchase and } \\
\text { I don't need my health insurance } \\
\text { charging me... }\end{array}$ & $\begin{array}{l}\text { It's just I don't want them using } \\
\text { it for different purposes, other } \\
\text { than what ... they were gonna } \\
\text { use it for. } \\
\text { I don't think they should be } \\
\text { able to use your-that informa- } \\
\text { tion against you as far as, } \\
\text { again, raising premiums or co- } \\
\text { pays or deciding what's a cov- } \\
\text { ered cost and what's not a cov- } \\
\text { ered cost based on my lifestyle } \\
\text { as far as what I eat. }\end{array}$ \\
\hline
\end{tabular}

\begin{abstract}
A doctor's office monitors internet search data of their patients and contacts individuals who search for symptoms of illness in order to provide an early diagnosis.
\end{abstract}

$12(27 \%)$

\begin{abstract}
...The doctor can be like hey, I seen you looked this up about measles and now all of a sudden you think you have measles -it's all in your head.

They can say, oh, I see that you're looking for information on a child that's throwing up chronically. Let's get him in here and check him out...
\end{abstract}

University researchers access the smartphone location and medical records of patients to study risk factors for cancer.
$35(78 \%) \quad$ I mean, that idea is something worth being monitored for because it's for a good cause. I mean, it can potentially save hundreds of lives, and it can also save insurance companies.

\begin{abstract}
A technology company creates an app that tracks users' locations and asks them to upload photos of their meals with the intention of encouraging healthy eating and sharing this information with advertisers who can provide users with coupons.
\end{abstract}

$27(60 \%)$

\begin{abstract}
I like that idea of if somebody wanted to do it so they don't get diabetes. Upload any pictures of the food you eat and get tips about what to do.

People have to actively want to use it and those individuals may want to receive grocery store coupons that are in line with the goals of losing weight, right? So I don't have a negative reaction to that.
\end{abstract}

They shouldn't have access to what I'm searching for online because I am a Web M.D. queen...I will Google the symptoms and see if it's something else or what I can do before I go to the doctor.

It's just an invasion of privacy. Again, if you are volunteering that information, then you can volunteer whatever information you want.

Just I don't like anyone knowing my whereabouts all hours of the day and all night, especially - and it's not even just anyone. It's - a stranger..

Personally, no, because I don't want them thinking because of where I work at that I'm buying tobacco all the time because I work at a store that sells tobacco and alcohol.

I would worry that in the future or - I think it's already possible to for them to sell the data to another company that could reverse engineer the data and result in higher insurance premiums for individuals and that sort of thing.

...Nothing would prevent me from taking a picture of the salad that my wife is eating and post that as my dinner, while I'm - in reality, I'm eating a big, thick juicy steak and baked potato...It seems like a lot of effort to go through, and I'm not sure what the benefit's going to be.
It would have to be on an optin basis so that people are made aware of what's gonna happen and they're choosing to let that happen

That should definitely be protected, because that's sensitive.

If there was a situation where I thought that someplace I went would give the wrong idea out of context, then just turn off GPS.

Just knowing that they are not allowed to sell my information for anything else other than using it specifically for this research.

They have to disclose exactly who they're sharing that information with outside of their company and the advertisers and what specific information they're sharing with those advertisers and the other third parties that may be involved.

I would think there would have to be a government mandate for a lot of transparency, including specific fines for misusing or not protecting the data.

${ }^{\mathrm{a}}$ Responses by participants to each scenario were coded as favorable, unfavorable, or neutral.

\section{Scenario 1}

Scenario 1 was a follows: A health insurance company accesses data on consumers' grocery store purchases to identify individuals at high risk for developing diabetes and sends them healthy eating tips.

Overall, 20 out of 45 participants (44\%) rated this program favorably. Participants liked the idea they could receive recommendations to improve their diet or management of their health conditions. Others thought the program could address population-level health problems in the United States or reduce insurance costs for those making healthy food choices. Participants were concerned by the motive of health insurers running such a program. They worried about losing insurance coverage or paying higher premiums based on their grocery purchases. Participants described protections they desired, 
including limits on other uses of data collected for this program, destruction of data after the program was complete, and opt-in and consent procedures for interested participants.

\section{Scenario 2}

Scenario 2 was as follows: A doctor's office monitors internet search data of their patients and contacts individuals who search for symptoms of illness in order to provide an early diagnosis.

Overall, 12 out of 45 participants $(27 \%)$ rated this program favorably. Participants identified several beneficial elements of this program, including the prevention of illness, possible savings on health care costs, convenience of care that could be provided remotely particularly for those with barriers to face-to-face care, and additional support from clinical providers for overall health. Additionally, participants liked that this scenario could provide patients with better quality information, preventing inaccurate self-diagnoses using web searches. Some participants felt that having a doctor access their searches would be too invasive, and they would rather conduct personal research and contact their provider if they had concerns. Some felt uncomfortable with the idea that their data could potentially be used for targeted drug or treatment advertising.

Participants emphasized the negative aspects of this scenario. Many were concerned about inadequate protections for their internet search data. They asked for full transparency and limits around the uses of their data, as well as personal data access. Participants also generally preferred that this program be opt-in and wanted assurances that there would be adequate data security safeguards in place.

\section{Scenario 3}

Scenario 3 was as follows: University researchers access the smartphone location and medical records of patients to study risk factors for cancer.

Overall, 35 out of 45 participants $(78 \%)$ rated this program favorably. Participants saw benefit in participating in any program that could lead to cancer prevention, often citing personal or family history as motivators for participation. Some viewed this scenario more favorably because consent is required for research participation. Some participants who did not approve felt that the data sharing required was an invasion of their privacy. In particular, some participants indicated that they were not comfortable with researchers having access to their medical records.

Participants suggested that researchers obtain additional consent to have their location tracked and that they have the ability to turn off their location sharing at will. Participants also indicated the importance of transparency, specifically that the location information was secure, was not sold to other companies, and was used solely for research purposes. Finally, participants desired data to be deidentified.

\section{Scenario 4}

Scenario 4 was as follows: A technology company creates an app that tracks users' locations and asks them to upload photos of their meals with the intention of encouraging healthy eating

and sharing this information with advertisers who can provide users with coupons.

Overall, 27 out of 45 participants $(60 \%)$ rated this program favorably. Those who responded favorably to this program thought it would help them to eat healthier and prevent diabetes, and many wanted to receive coupons for using the app. A few appreciated the voluntary or opt-in nature of the app. Others were mistrustful of the motives and felt that only the company or insurers would benefit.

Many participants did not want their information to be sold to advertising companies. Some would not participate because of the inconvenience of having to use the app consistently or the nuisance of receiving advertisements. Others had privacy concerns and worried about downstream use of their information for other purposes. For many, the only desired protection was the ability to either opt-in or opt-out of the app. Finally, participants discussed the importance of anonymity and the ability to use the app without advertisers or third parties identifying them.

\section{Discussion}

\section{Principal Findings}

In a broadly representative sample of US consumers, we examined attitudes and knowledge about digital health privacy. We identified several key findings. First, participants generally did not draw connections between the data they leave behind when they use digital technology and what it may reveal about their health. Second, participants struggled to weigh harms and benefits of data collection and use. Third, while preferences varied, participants generally wanted some protections in place for health-relevant consumer digital data.

Prior work has demonstrated that consumers value privacy but nonetheless continue to use digital technologies that routinely compromise that privacy [19]. Turow et al argued that this behavior should not be interpreted as consumers being unconcerned with privacy, but rather a sense of resignation that threats to privacy are unavoidable [20]. Our findings suggest that consumers often recognize that information is shared when they use digital technology but are often unaware of the extent of use or what can be learned about them from their data. Obar et al demonstrated that simply presenting consumers with more information will not necessarily lead to more informed consumers or yield higher quality decision making. In an experiment simulating registration with a social networking program, they found that consumers viewed lengthy privacy policies as a nuisance, felt overburdened by privacy statements, and missed "gotcha" provisions that were extreme (eg, many consented to give up their first-born child) [21].

Given that many consumers rank health privacy above other areas [22], it is concerning that most participants in our study could not draw connections between consumer digital data and inferences about their health. Broadly available analytic tools allow for the health status to be inferred from a wide range of data sources including smart devices in the home, language analysis from social media, financial spending habits, and internet search patterns $[7,8,23]$. Even when health applications 
were made explicit in the study scenarios, the tradeoffs between threats to privacy and benefits of use remained difficult for our study participants to reconcile. The difficulty assessing tradeoffs is likely compounded by the absence of limits on data use and the uncertain risks posed. Conger et al have argued that the relationships between consumers and businesses have become too complex for the individual consumer to assess given the involvement of third-party data brokers and open-ended uses of data [24].

Facing vignettes about commercial users, participants often raised concerns about economic harms (eg, higher insurance premiums and threats to employment) as well as unbridled secondary uses of their data. When considering vignettes with researchers and doctors as the data users, participants were often concerned with reputational harms (eg, sharing of embarrassing or unflattering information) [25]. Overall, participants responded much more favorably to some scenarios over others suggesting that consumers apply a nuanced evaluation of the use, including whether it is beneficial to themselves, the type of data that is being used, who is using their data, and the overall benefit of the use.

Participants sought privacy safeguards to reconcile the tradeoffs between health benefits and privacy. Many of the safeguards raised mirror those that have been part of the EU General Data Protection Regulation, including consent for data collection and use (opt-in), explicit statements of what data would be used for and by whom, limits on data transfer and selling, and data security requirements [26]. Participants were overwhelmingly in favor of protections for their digital health data. However, prior work points to practical limitations on the effectiveness of some of these approaches. For example, consumers often click through overly complex privacy agreements, suggesting a vastly simplified approach would be needed [20]. Policymakers might consider varying privacy protections based on the associated risks and benefits of different uses or curtail downstream transfers and aggregation of data that are far removed from the original point of collection.

\section{Limitations}

This study has several limitations. Digital privacy is a topic with growing relevance and has been increasingly highlighted in popular media, which could shape consumers' attitudes. Events just prior to interviews may have heavily influenced participants' knowledge and perceptions. Therefore, the interviews reflect the time period (2018-2019) in which they were conducted. Despite efforts to recruit consumers with a wide range of characteristics, consumers who were willing to respond to and complete a request for an interview may have characteristics or attitudes not shared by those who chose not to participate. Social desirability bias may limit the credibility of participants' expressed views. Despite these limitations, the interviews show a diverse array of attitudes regarding digital privacy.

\section{Conclusions}

This study reveals how individual consumers wish to protect their own health information privacy and how little they are aware of the threats to that privacy from their conventional behaviors. Digital personal health information is now derived from consumer engagements as well as medical engagements. To the extent we need protections for personal health privacy, those protections need to extend beyond their current reach. Our study reinforces the finding that a purely market-based approach to privacy that depends on rational consumers making decisions with full information relies on faulty assumptions [27]. Future debates in the United States may need to focus on whether more robust privacy standards (similar to the European Union's General Data Protection Regulation) are needed to protect consumer digital data from entities beyond health care systems [28,29].

\section{Acknowledgments}

This research was supported by the National Human Genome Research Institute/National Institutes of Health (NIH) (5R01HG009655-04). The funder had no role in the design and conduct of the study; collection, management, analysis, and interpretation of the data; preparation, review, or approval of the manuscript; and decision to submit the manuscript for publication. We thank Ashley Lewson for her role in conducting and coding interviews.

\section{Conflicts of Interest}

DAA is a partner at VAL Health. The other authors have no conflicts to declare.

\section{Multimedia Appendix 1}

Interview guide.

[DOCX File, 27 KB-Multimedia Appendix 1]

\section{References}

1. Digital 2020: 3.8 Billion People Use Social Media. We Are Social. URL: https://wearesocial.com/blog/2020/01/ digital-2020-3-8-billion-people-use-social-media [accessed 2021-02-12]

2. Kaplan B. Seeing Through Health Information Technology: The Need for Transparency in Software, Algorithms, Data Privacy, and Regulation. SSRN Journal 2020 Oct 09;7(1):1-18. [doi: 10.2139/ssrn.3672395]

3. McIver DJ, Hawkins JB, Chunara R, Chatterjee AK, Bhandari A, Fitzgerald TP, et al. Characterizing Sleep Issues Using Twitter. J Med Internet Res 2015 Jun 08;17(6):e140-e140 [FREE Full text] [doi: 10.2196/jmir.4476] [Medline: 26054530] 
4. Card C. How Facebook AI Helps Suicide Prevention. Facebook. 2018. URL: https://about.fb.com/news/2018/09/ inside-feed-suicide-prevention-and-ai/ [accessed 2021-01-13]

5. De Choudhury M, Counts S, Horvitz E. Social media as a measurement tool of depression in populations. In: WebSci '13: Proceedings of the 5th Annual ACM Web Science Conference. 2013 May Presented at: 5th Annual ACM Web Science Conference; May 2-4, 2013; Paris, France p. 47-56. [doi: 10.1145/2464464.2464480]

6. Eichstaedt JC, Smith RJ, Merchant RM, Ungar LH, Crutchley P, Preoţiuc-Pietro D, et al. Facebook language predicts depression in medical records. Proc Natl Acad Sci U S A 2018 Oct 30;115(44):11203-11208 [FREE Full text] [doi: 10.1073/pnas.1802331115] [Medline: 30322910]

7. Grande D, Luna Marti X, Feuerstein-Simon R, Merchant RM, Asch DA, Lewson A, et al. Health Policy and Privacy Challenges Associated With Digital Technology. JAMA Netw Open 2020 Jul 01;3(7):e208285-e208285 [FREE Full text] [doi: 10.1001/jamanetworkopen.2020.8285] [Medline: 32644138]

8. All Your Data Is Health Data. The New York Times. 2019. URL: https://www.nytimes.com/2019/08/13/opinion/health-data. html [accessed 2020-02-11]

9. Sonn JW. Coronavirus: South Korea's success in controlling disease is due to its acceptance of surveillance. The Conversation. 2020. URL: http://theconversation.com/ coronavirus-south-koreas-success-in-controlling-disease-is-due-to-its-acceptance-of-surveillance-134068 [accessed 2021-02-20]

10. Stokes DC, Andy A, Guntuku SC, Ungar LH, Merchant RM. Public Priorities and Concerns Regarding COVID-19 in an Online Discussion Forum: Longitudinal Topic Modeling. J Gen Intern Med 2020 Jul 12;35(7):2244-2247 [FREE Full text] [doi: 10.1007/s11606-020-05889-w] [Medline: 32399912]

11. Guntuku SC, Sherman G, Stokes DC, Agarwal AK, Seltzer E, Merchant RM, et al. Tracking Mental Health and Symptom Mentions on Twitter During COVID-19. J Gen Intern Med 2020 Sep 07;35(9):2798-2800 [FREE Full text] [doi: 10.1007/s11606-020-05988-8] [Medline: 32638321]

12. Schechner S, Winkler R. Here's How Apple and Google Plan to Track the Coronavirus Through Your Phone. The Wall Street Journal. 2020. URL: https://www.wsj.com/articles/heres-how-apple-and-google-plan-to-track-the-coronavirusthrough-your-phone-11586618075 [accessed 2020-11-20]

13. Budd J, Miller BS, Manning EM, Lampos V, Zhuang M, Edelstein M, et al. Digital technologies in the public-health response to COVID-19. Nat Med 2020 Aug 07;26(8):1183-1192. [doi: 10.1038/s41591-020-1011-4] [Medline: 32770165]

14. Auxier B, Rainie L, Anderson M, Perrin A, Kumar M, Turner E. Americans and Privacy: Concerned, Confused and Feeling Lack of Control Over Their Personal Information. Pew Research Center. 2019. URL: https://www.pewresearch.org/internet/ 2019/11/15/americans-and-privacy-concerned-confused-and-feeling-lack-of-control-over-their-personal-information/ [accessed 2020-09-20]

15. KnowledgePanel: A Methodological Overview. IPSOS. URL: https://www.ipsos.com/sites/default/files/ ipsosknowledgepanelmethodology.pdf [accessed 2020-01-18]

16. Institute of Medicine, Committee on Regional Health Data Networks, Donaldson MS, Lohr KN. Health Data in the Information Age: Use, Disclosure, and Privacy. Washington, DC: The National Academies Press; 1994.

17. NVivo Qualitative Data Analysis Software. QSR International. URL: https://www.qsrinternational.com/ nvivo-qualitative-data-analysis-software/home [accessed 2020-03-20]

18. Braun V, Clarke V. Using thematic analysis in psychology. Qualitative Research in Psychology 2006 Jan 1;3(2):77-101. [doi: 10.1191/1478088706qp063oa]

19. Madden M, Rainie L. Americans' Views About Data Collection and Security. Pew Research Center. 2015. URL: https:/ /www.pewresearch.org/internet/2015/05/20/americans-views-about-data-collection-and-security/ [accessed 2021-02-11]

20. Turow J, Hennessy M. The Tradeoff Fallacy: How Marketers are Misrepresenting American Consumers and Opening Them Up to Exploitation. SSRN Journal 2015 Jun 1:1-24. [doi: 10.2139/ssrn.2820060]

21. Obar JA, Oeldorf-Hirsch A. The biggest lie on the Internet: ignoring the privacy policies and terms of service policies of social networking services. Information, Communication \& Society 2018 Jul 03;23(1):128-147. [doi: 10.1080/1369118x.2018.1486870]

22. Madden M. Americans Consider Certain Kinds of Data to be More Sensitive than Others. Pew Research Center. 2014. URL: https://www.pewresearch.org/internet/2014/11/12/ americans-consider-certain-kinds-of-data-to-be-more-sensitive-than-others/ [accessed 2021-02-11]

23. Fussell S. Google's Totally Creepy, Totally Legal Health-Data Harvesting. The Atlantic. 2019. URL: https://www. theatlantic.com/technology/archive/2019/11/google-project-nightingale-all-your-health-data/601999/ [accessed 2021-11-02]

24. Conger S, Pratt J, Loch K. Personal information privacyemerging technologies. Information Systems Journal 2013;23(5):401-417. [doi: 10.1111/j.1365-2575.2012.00402.x]

25. Prasad A, Sorber J, Stablein T, Anthony D, Kotz D. Understanding sharing preferences and behavior for mHealth devices. In: WPES '12: Proceedings of the 2012 ACM Workshop on Privacy in the Electronic Society. 2012 Oct Presented at: 2012 ACM Workshop on Privacy in the Electronic Society; October 15, 2012; Raleigh, NC p. 117-128. [doi: $10.1145 / 2381966.2381983]$ 
26. Voigt P, von dem Bussche A. The EU General Data Protection Regulation (GDPR). New York, NY: Springer Publishing; 2017.

27. Park YJ. Does a market-approach to online privacy protection result in better protection for users? The Policy and Internet Blog. 2015. URL: https://blogs.oii.ox.ac.uk/policy/

does-a-market-approach-to-online-privacy-protection-result-in-better-protection-for-users/ [accessed 2021-03-20]

28. Orlando AW, Rosoff AJ. The New Privacy Crisis: What's Health Got to Do with It? Am J Med 2019 Feb;132(2):127-128. [doi: 10.1016/j.amjmed.2018.09.033] [Medline: 30367855]

29. Gostin LO, Halabi SF, Wilson K. Health Data and Privacy in the Digital Era. JAMA 2018 Jul 17;320(3):233-234. [doi: 10.1001/jama.2018.8374] [Medline: 29926092]

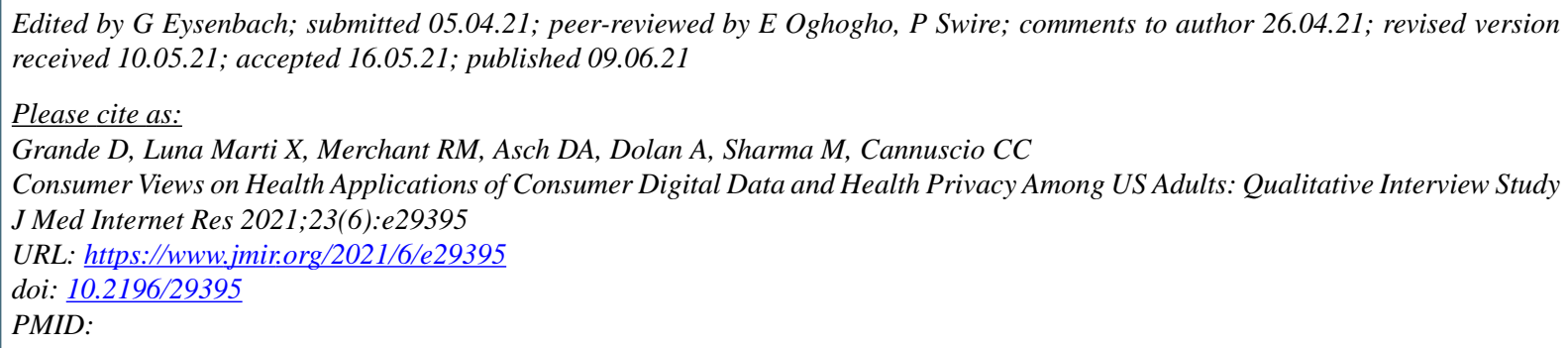

(CDavid Grande, Xochitl Luna Marti, Raina M Merchant, David A Asch, Abby Dolan, Meghana Sharma, Carolyn C Cannuscio. Originally published in the Journal of Medical Internet Research (https:/www.jmir.org), 09.06.2021. This is an open-access article distributed under the terms of the Creative Commons Attribution License (https://creativecommons.org/licenses/by/4.0/), which permits unrestricted use, distribution, and reproduction in any medium, provided the original work, first published in the Journal of Medical Internet Research, is properly cited. The complete bibliographic information, a link to the original publication on https://www.jmir.org/, as well as this copyright and license information must be included. 